\title{
Comparative Heat Transfer Efficiency Study of Coaxial and U-loop Boreholes
}

\author{
Jun Wang Ph. D
}

\begin{abstract}
This paper presents the results of comparative heat transfer efficiency study based on in situ full scale tests conducted on conventional $U$-loop borehole heat exchangers (BHE) and a coaxial BHE. The results show that the coaxial BHE has considerably higher heat transfer efficiency, while consuming less pumping power than the U-loop's. The implication of a high efficiency BHE on reducing borehole loop length and initial investment cost is also discussed. It is concluded that the higher efficiency coaxial BHE has the potential to reduce borehole length $30 \%$ to $50 \%$.
\end{abstract}

Index Terms - Borehole Heat Exchanger (BHE), Coefficient of Performance (COP), Ground Source Heat Pump (GSHP), Specific Energy Extraction

\section{INTRODUCTION}

A $\mathrm{n}$ important issue in the design of ground source heat pump (GSHP) system is to find cost effective methods to construct the borehole heat exchanger, so that heat can be injected to or extracted from the ground without excessive temperature differences between the heat carrier fluid and the surrounding ground. It is reported that a reduction of $1{ }^{\circ} \mathrm{C}$ in the temperature difference between the ground and the evaporator of a GSHP system can increase the heat pump Coefficient of Performance (COP) by $2 \%$ to $3 \%$ [1].

Vertical ground heat exchangers are classified based on their cross-sectional geometry and how the heat exchange from the flow channels takes place. Fig. 1 shows the two fundamental designs, i.e., the U-loop pipe and the coaxial pipe. Hellstrom has a thorough review on different types of BHE design and grouting techniques [2].

In the U-loop type borehole heat exchanger, both the downward and the upward flow channels participate in the heat exchange with the surrounding ground. U-loop type BHE has been designed with two or more channels. The double Uloop BHE has become increasingly popular, with increasing drilling depth, due to its lower thermal resistance and head loss [3].

The characteristics of the coaxial (also called tube-in-tube) type BHE is that heat exchange occurs in only one channel of flow, either the upstream or downstream, through the annular space between the inner pipe and the outer pipe walls. The flow direction may also be different during injection or

J. Wang is with McClymont \& Rak Engineers, Inc., Vaughan, ON M1V 4X9 Canada (phone: 416-675-0160; fax: 905-851-1722; e-mail: jwang@ mccrak.com). extraction of heat transfer. The inner pipe is often thermally insulated in order to avoid thermal short-circuiting between the upward and downward flow channels. Coaxial borehole heat exchangers may be designed with or without outer tube, i.e., as a closed or open flow circuit.
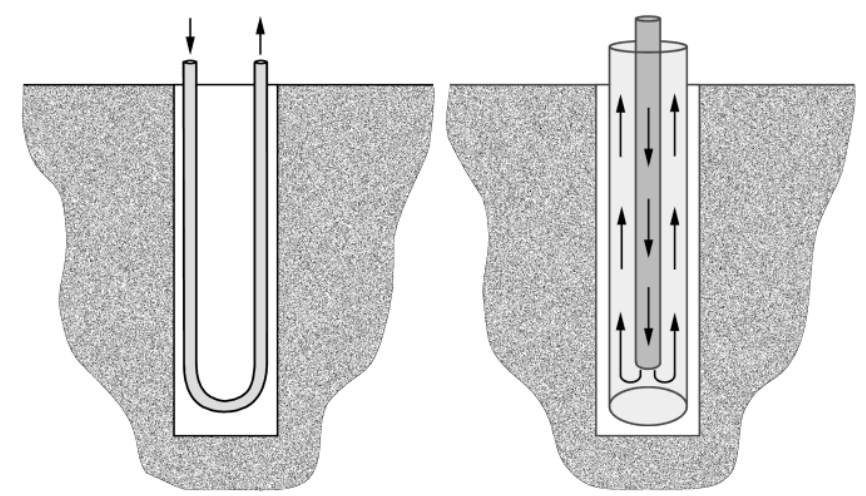

Figure 1. The two fundamental BHE design - the U-loop and coaxial pipe.

Open borehole heat exchanger is very favorable from a heat transfer point-of-view because the heat transfer fluid can be in direct contact with the borehole wall. The borehole thermal resistance with turbulent flow conditions $(\mathrm{Re} \approx 9000)$ was verified to be around $0.01{ }^{\circ} \mathrm{C} /(\mathrm{W} / \mathrm{m})$. However, a closed system is often required due to geochemical concerns [2].

Another concern of open-loop BHE is associated with possible freezing in the well during continuous operation in very cold climates. Minea conducted experimental study recently on standing column heat pump without bleed to determine its feasibility in Quebec, Canada. The conclusion of his study is that open-loop BHE could not compete with the closed-loop and is not applicable in cold climates [4].

This paper studies heat transfer efficiency of coaxial borehole heat exchanger based on comparative in situ full scale tests in heating mode and cooling mode conducted on the coaxial BHE and the conventional U-loop BHE. The resulted GSHP system COP of each test is analyzed and the pumping costs of the two pipes are compared. The implication of a high efficiency BHE on reducing borehole loop length and initial investment cost is also discussed.

\section{THE GSHP SYSTEM AT ECOFARM}

EcoFarm is located in Caledon, Ontario, Canada, at $43.914^{\circ} \mathrm{N}, 79.865^{\circ} \mathrm{W}$. The borehole revealed some $20 \mathrm{~m}$ of 
sand deposit followed by sand and gravel from $20 \mathrm{~m}$ depth to about $64 \mathrm{~m}$ depth. The sand and gravel is underlain by sedimentary shale/limestone bedrock formation. Static groundwater level is at depth of about $30 \mathrm{~m}$ below surface. The undisturbed underground temperature $T_{0}$ is $8.92{ }^{\circ} \mathrm{C}$.

\section{A. The Installed BHE}

The GSHP system installed at the EcoFarm for research, constituted of $\mathrm{BH} 2, \mathrm{BH} 3$ and $\mathrm{BH} 4$ in Fig. 2, is a stand-alone water-to-water system, which is convertible, if required for dumping excess heat, to water-to-air. Three $80 \mathrm{~m}$ deep wells with different pipe/grout assembly are connected to a $24 / 7$ year round monitoring header and to a $5 \mathrm{~T}$ ClimateMaster. The total installed BHE length is $240 \mathrm{~m}$, undersized when compared to the required depth to run a $5 \mathrm{~T}$ heat pump (HP) system by the rule of thumb " $60 \mathrm{~m}$ per ton of refrigeration".

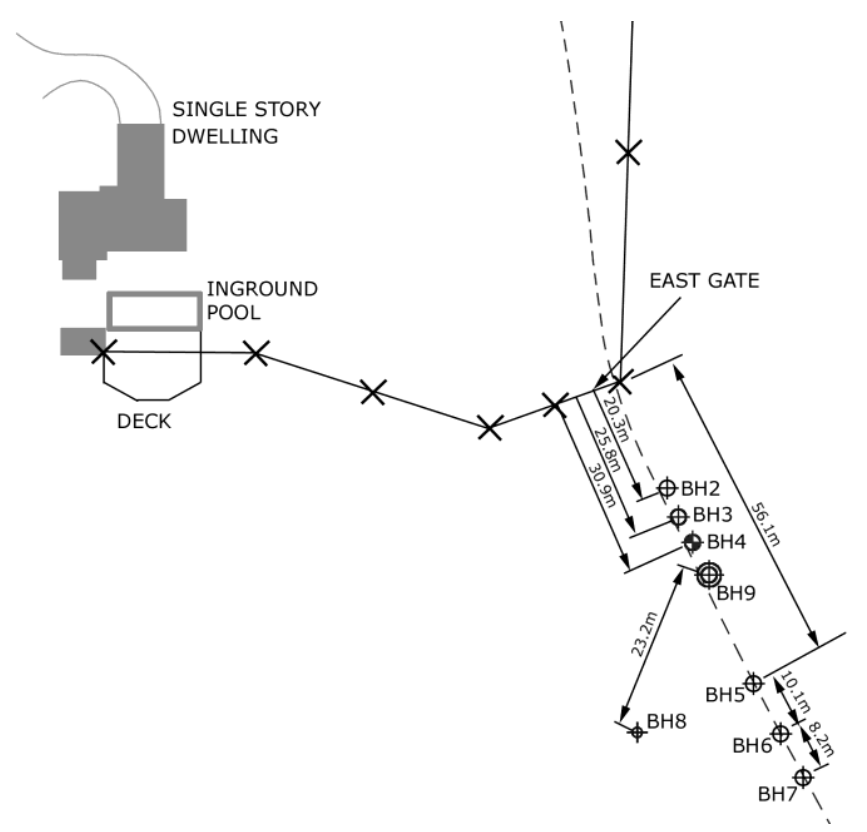

Figure 2. Borehole Location plan at EcoFarm.

The borehole heat exchangers in $\mathrm{BH} 2$ and $\mathrm{BH} 3$ were installed with high density plastic U-loop pipes. The outer diameter of the U-loop pipe is $42 \mathrm{~mm}$, and the inner diameter, $35 \mathrm{~mm}$. $\mathrm{BH} 2$ is a conventional $\mathrm{BHE}$ system, whereas $\mathrm{BH} 3$ is also a conventional BHE system completed with an experimental super grout.

BH4 was installed with a coaxial heat exchanger. The design consists of an outer pipe of fibre glass reinforced plastic (FRP), and an inner pipe of PVC. The inside diameter of inner and outer pipes are approximately $43 \mathrm{~mm}$ and $84 \mathrm{~mm}$, respectively. The heat transfer fluid flows into the header assembly, down the inside of the inner pipe, and then back up the borehole in the annulus between the two pipes. The heat transfer efficiency of the coaxial BHE is claimed to be higher than conventional U-loop BHE due to the higher thermal conductivity of outer pipe material, thermally insulative inner pipe material and large outer pipe surface contact with surrounding soil.

Based on borehole thermal resistance test conducted earlier at Ecofarm installation, BHE resistance for the U-loop BHE at $\mathrm{BH} 3$ is $0.1390{ }^{\circ} \mathrm{C} /(\mathrm{W} / \mathrm{m})$, whereas for the coaxial $\mathrm{BHE}$ at $\mathrm{BH} 4,0.0971{ }^{\circ} \mathrm{C} /(\mathrm{W} / \mathrm{m})$. Therefore, the coaxial borehole exchanger resistance value is about $30 \%$ lower than that of conventional U-loop.

\section{B. The Monitoring System}

The monitoring setup of the GSHP system is shown in Fig.3. Data loggers by HOBO were connected to temperature and electricity power consumption monitoring devices to record targeted information at every 12 seconds. A Wattnode Pulse electricity usage meter is used to track the total electricity usage of the heat pump. Attached to the piping are Resistant Temperature Detector (RTD) sensors that relay the recorded temperatures to the HOBO data logger. A weather station located on the outside of the building provides real time temperature and humidity verification.

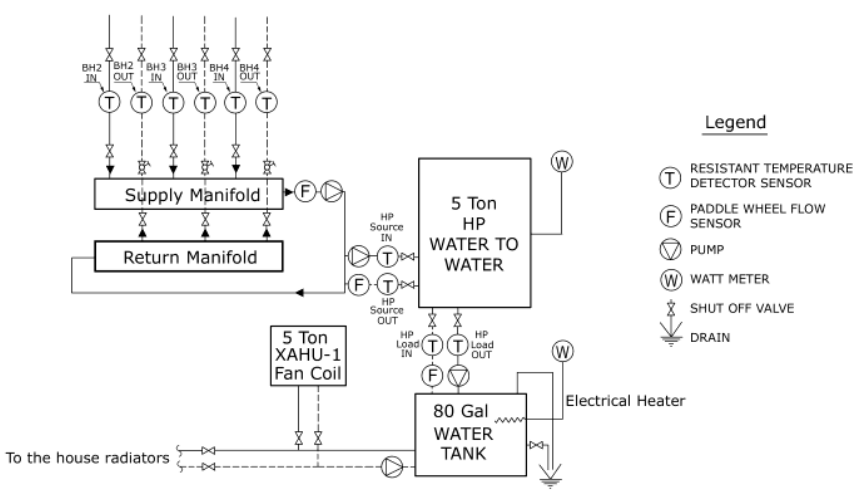

Figure 3. Ground source heat pump and monitoring system.

\section{TEST RESUltS}

Comparative, full scale, in situ performance test on the coaxial and the U-loop borehole exchangers was carried out during August to October, 2012. Cooling and heating mode tests were conducted on the single coaxial BHE (BH4) and the twin conventional U-loop BHEs (BH2 \& $\mathrm{BH} 3)$, separately, in order to assess performances of the two types of borehole heat exchangers.

With preliminary promising result obtained from the tests, another set of cooling tests were conducted during August to September, 2013, specifically to further compare performance of the single coaxial BHE against the single U-loop BHE. Therefore, the tests were conducted for three scenarios, i.e., the single coaxial $\mathrm{BH} 4$, the single $\mathrm{U}$-loop $\mathrm{BH} 3$, and the twin U-loop BH2 \& BH3.

Test load demand was created by an air handler unit timed on a 30 minutes on/off cycle during daytime to model the realistic operation condition. The flow rate was $15 \mathrm{GPM}$ at HP source, and 10.5 GPM at HP load for all the tests.

\section{A. Temperature Response Curves}

Full temperature responses together with HP electricity consumption were monitored continuously. As examples, Fig. 
4 and Fig. 5 show typical HP temperature response curves in heating mode tests for the single coaxial BHE and the twin Uloop BHEs tests respectively. HP electricity consumption power is also displayed in the graphs. A running cycle usually lasted for 20-25 minutes, and similar curves for the two sets of test are observed. The statistical comparisons of the results are discussed below.

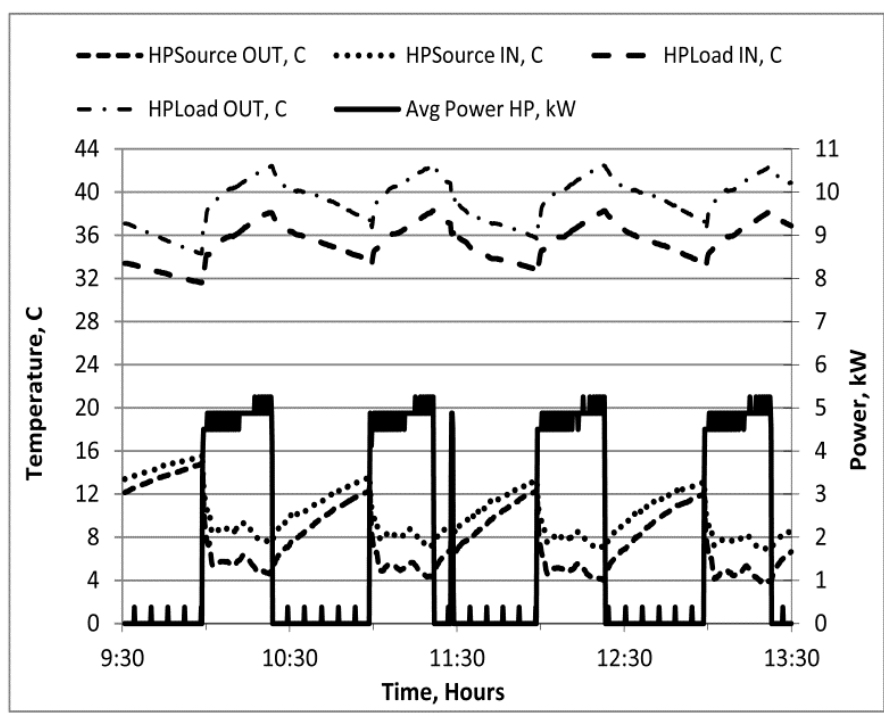

Figure 4. Typical Single coaxial BHE heating mode monitoring curves .

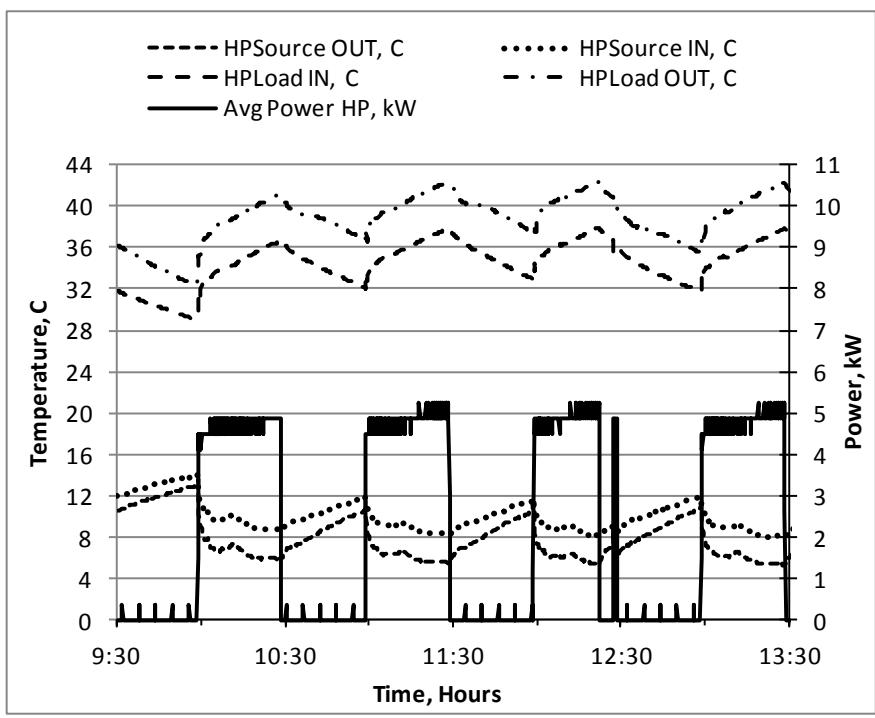

Figure 5. Typical twin U-loop BHE heating mode monitoring curves.

\section{B. Heating and Cooling Tests 2012}

The mean values of the monitored temperature responses and the calculated energy transfer amount at HP source input and HP load output together with electricity consumption are summarized in Table I and Table II respectively. In these tables, EWT stands for Entering Water Temperature, and LWT stands for Leaving Water Temperature. $\dot{W}_{\mathrm{C}}$ is the energy (electricity) consumption power of the compressor.
$\dot{Q}_{\text {source }}$ and $\dot{Q}_{\text {load }}$ are the energy transfer rate at HP Source end (ground) and Load end (house). $\dot{q}_{\text {source }}$ is the specific heat transfer rate of $\mathrm{BHE}$.

In heating mode tests, the mean working fluid temperature in the coaxial BHE test was $6.4{ }^{\circ} \mathrm{C}$, about $3{ }^{\circ} \mathrm{C}$ lower than that of the twin U-loop BHE test, when the specific heat extraction rate from the ground was doubled. In cooling mode tests, working fluid temperature in the coaxial BHE test was 18.6 ${ }^{\circ} \mathrm{C}$, about $2{ }^{\circ} \mathrm{C}$ higher than that of the twin U-loop BHE test. The HP performance COP for the single coaxial was $4 \%$ and $6 \%$ lower than the twin U-loop's, in heating and cooling mode tests respectively. The results indicate very competitive heat transfer efficiency of coaxial over conventional U-loop borehole heat exchangers, when about $95 \%$ of system efficiency was achieved for the coaxial BHE at half borehole length, or double heat exchange rate with the ground, of that of the U-loop. As the efficiency of the single U-loop was not tested at this point, we decided to conduct another set of tests to verify the efficiency of the coaxial BHE.

TABLE I. TEMPERATURE RESPONSES IN 2012 TeStS $\left({ }^{\circ} \mathrm{C}\right)$

\begin{tabular}{|c|c|c|c|c|c|c|c|c|}
\hline \multicolumn{2}{|c|}{ Test } & BH2 & BH3 & BH4 & $\begin{array}{c}\text { HP } \\
\text { Source }\end{array}$ & $\begin{array}{c}\Delta \mathrm{T} \\
\text { Source } \\
\end{array}$ & $\begin{array}{c}\text { HP } \\
\text { Load }\end{array}$ & $\begin{array}{c}\Delta \mathrm{T} \\
\text { Load }\end{array}$ \\
\hline \multirow{2}{*}{$\begin{array}{l}\text { Single } \\
\text { coaxial } \\
\text { Heating }\end{array}$} & EWT & & & 7.1 & 7.8 & \multirow{2}{*}{2.6} & 36.1 & \multirow{2}{*}{4.1} \\
\hline & LWT & & & 5.7 & 5.2 & & 40.1 & \\
\hline \multirow{2}{*}{$\begin{array}{c}\text { Twin } \\
\text { U-loop } \\
\text { Heating }\end{array}$} & EWT & 10.1 & 10.7 & & 9.9 & \multirow{2}{*}{2.7} & 35.8 & \multirow{2}{*}{4.3} \\
\hline & LWT & 7.9 & 9.1 & & 7.2 & & 40.1 & \\
\hline \multirow{2}{*}{$\begin{array}{c}\text { Single } \\
\text { coaxial } \\
\text { Cooling }\end{array}$} & EWT & & & 16.6 & 17.4 & \multirow{2}{*}{3.5} & 10.2 & \multirow{2}{*}{3.6} \\
\hline & LWT & & & 20.7 & 20.9 & & 6.6 & \\
\hline \multirow{2}{*}{$\begin{array}{c}\text { Twin } \\
\text { U-loop } \\
\text { Cooling }\end{array}$} & EWT & 15.0 & 15.2 & & 15.0 & \multirow{2}{*}{3.5} & 10.0 & \multirow{2}{*}{3.7} \\
\hline & LWT & 17.8 & 18.2 & & 18.5 & & 6.3 & \\
\hline
\end{tabular}

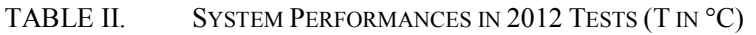

\begin{tabular}{|c|c|c|c|c|c|c|c|c|}
\hline Test & $\begin{array}{c}\text { Out- } \\
\text { door T }\end{array}$ & $\begin{array}{c}\text { EWT } \\
\text { Source }\end{array}$ & $\begin{array}{c}\dot{Q}_{\text {source }} \\
(\mathbf{k W})\end{array}$ & $\begin{array}{c}\dot{q}_{\text {soure }} \\
\mathbf{( W / m})\end{array}$ & $\begin{array}{c}\dot{Q}_{\text {load }} \\
(\mathbf{k W})\end{array}$ & $\begin{array}{c}\dot{W}_{\mathrm{C}} \\
(\mathbf{k W})\end{array}$ & $\mathbf{C O P}$ & $\mathbf{\%}$ \\
\hline $\begin{array}{c}\text { Single } \\
\text { coaxial } \\
\text { Heating }\end{array}$ & 15.8 & 7.8 & 10.1 & 126 & 11.2 & 4.7 & 2.4 & 95.6 \\
\hline $\begin{array}{c}\text { Twin } \\
\text { U-loop } \\
\text { Heating }\end{array}$ & 12.8 & 9.9 & 10.5 & 66 & 11.8 & 4.7 & 2.5 & 100 \\
\hline \hline $\begin{array}{c}\text { Single } \\
\text { coaxial } \\
\text { Cooling }\end{array}$ & 22.4 & 17.4 & 13.8 & 173 & 10.0 & 3.1 & 3.3 & 93.9 \\
\hline $\begin{array}{c}\text { Twin } \\
\text { U-loop } \\
\text { Cooling }\end{array}$ & 20.6 & 15.0 & 13.7 & 86 & 10.1 & 2.9 & 3.5 & 100 \\
\hline
\end{tabular}

\section{Cooling Tests 2013}

The mean values of the monitored temperature responses and the calculated energy transfer amount at HP source input and HP load output together with electricity consumption for cooling tests conducted in 2013 are summarized in Table III and Table IV respectively. Mean working fluid temperatures were $17.4{ }^{\circ} \mathrm{C}, 17.9{ }^{\circ} \mathrm{C}$ and $23.3{ }^{\circ} \mathrm{C}$ in the twin U-loop BHE test, single coaxial BHE test and single U-loop BHE test 
respectively. Consequently, HP performance of the single coaxial BHE test could reach $96 \%$ of the twin U-loop BHE test performance, whereas the HP performance of the single U-loop BHE could only achieve $78 \%$ of the twin U-loop's.

When the same borehole length of single U-loop BHE and single coaxial BHE tests are examined, their specific heat transfer rate with the ground are at the same level, i.e., $200 \mathrm{~W} / \mathrm{m}$. The estimated characteristic parameters of fluid flow and heat transfer for the two types of pipes are listed in Table $\mathrm{V}$ for comparison.

TABLE III. TEMPERATURE RESPONSES IN 2013 COOLING TESTS $\left({ }^{\circ} \mathrm{C}\right)$

\begin{tabular}{|c|c|c|c|c|c|c|c|c|}
\hline \multicolumn{2}{|c|}{ Test } & \multirow[t]{2}{*}{ BH2 } & \multirow[t]{2}{*}{ BH3 } & \multirow{2}{*}{$\begin{array}{c}\text { BH4 } \\
15.4\end{array}$} & \multirow{2}{*}{$\begin{array}{c}\begin{array}{c}\text { HP } \\
\text { Source }\end{array} \\
16.4 \\
\end{array}$} & \multirow{3}{*}{$\begin{array}{c}\begin{array}{c}\Delta \mathbf{T} \\
\text { Source }\end{array} \\
4.0\end{array}$} & \multirow{2}{*}{$\begin{array}{c}\begin{array}{c}\text { HP } \\
\text { Load }\end{array} \\
15.2\end{array}$} & \multirow{3}{*}{\begin{tabular}{|c|}
$\begin{array}{c}\Delta \mathbf{T} \\
\text { Load }\end{array}$ \\
4.4
\end{tabular}} \\
\hline \multirow{2}{*}{$\begin{array}{l}\text { Single } \\
\text { coaxial }\end{array}$} & EWT & & & & & & & \\
\hline & LWT & & & 20.3 & 20.4 & & 10.8 & \\
\hline \multirow{2}{*}{$\begin{array}{l}\text { Single } \\
\text { U-loop }\end{array}$} & EWT & & 20.3 & & 22.2 & \multirow{2}{*}{4.3} & 15.5 & \multirow{2}{*}{4.2} \\
\hline & LWT & & 26.3 & & 26.5 & & 11.3 & \\
\hline \multirow{2}{*}{$\begin{array}{c}\text { Twin } \\
\text { U-loop }\end{array}$} & EWT & 15.5 & 15.6 & & 15.7 & \multirow{2}{*}{4.1} & 15.5 & \multirow{2}{*}{4.6} \\
\hline & LWT & 19.1 & 19.2 & & 19.8 & & 10.9 & \\
\hline
\end{tabular}

TABle IV. System Performances IN 2013 CoOloing Tests $\left(\mathrm{T} \mathrm{IN}^{\circ} \mathrm{C}\right)$

\begin{tabular}{|c|c|c|c|c|c|c|c|c|}
\hline Test & $\begin{array}{c}\text { Out- } \\
\text { door T }\end{array}$ & $\begin{array}{c}\mathbf{E W T} \\
\text { Source }\end{array}$ & $\begin{array}{c}\dot{Q}_{\text {soure }} \\
(\mathbf{k W})\end{array}$ & $\begin{array}{c}\dot{q}_{\text {soure }} \\
(\mathbf{W} / \mathbf{m})\end{array}$ & $\begin{array}{c}\dot{Q}_{\text {load }} \\
(\mathbf{k W})\end{array}$ & $\begin{array}{c}\dot{W}_{\mathrm{C}} \\
(\mathbf{k W})\end{array}$ & $\mathbf{C O P}$ & $\mathbf{\%}$ \\
\hline $\begin{array}{c}\text { Single } \\
\text { coaxial }\end{array}$ & 19.3 & 16.4 & 16.0 & 200 & 12.3 & 2.9 & 4.3 & 96.2 \\
\hline $\begin{array}{c}\text { Single } \\
\text { U-loop }\end{array}$ & 21.1 & 22.2 & 16.8 & 210 & 11.4 & 3.2 & 3.5 & 78.6 \\
\hline $\begin{array}{c}\text { Twin } \\
\text { U-loop }\end{array}$ & 23.2 & 15.7 & 16.2 & 101 & 12.6 & 2.8 & 4.5 & 100 \\
\hline
\end{tabular}

TABLE V. HEAT TRANSFER PARAMETERS OF U-LOOP AND COAXIAL

\begin{tabular}{|l|c|c|}
\hline \multicolumn{1}{|c|}{ Parameters } & BH4 coaxial & BH3 U-loop \\
\hline Working fluid flow rate $(\mathrm{GPM})$ & 14.5 & 11 \\
\hline Working fluid velocity $(\mathrm{m} / \mathrm{s})$ & 0.22 & 0.72 \\
\hline Reynolds number $\mathrm{Re}$ & 7000 & 19000 \\
\hline Nusselt number $\mathrm{Nu}$ & 6.9 & 4.2 \\
\hline Convective heat transfer coefficient $\left(\mathrm{W} / \mathrm{m}^{2 \circ} \mathrm{C}\right)$ & 100 & 70 \\
\hline Average temperature difference at $\mathrm{BH}$ wall $\left({ }^{\circ} \mathrm{C}\right)$ & 9.0 & 14.4 \\
\hline
\end{tabular}

It is observed from the Reynolds numbers that flows in both coaxial and U-loop pipes are turbulent. The Nusselt number of the coaxial BHE is about $60 \%$ higher than the U-loop's, indicating superior convective heat transfer ability across the pipe boundary.

A considerably higher temperature difference between the ground and the working fluid was resulted for the single Uloop BHE test than that for the single coaxial BHE test. The results confirmed significant higher heat transfer efficiency of the coaxial pipe over the conventional U-loop pipe.

\section{Pumping Costs}

The coaxial BHE is required to operate under a higher flow rate, i.e., 10-18 GPM, to achieve heat transfer efficiency mobilized by turbulence. A question arises as if higher pumping cost is needed for the coaxial BHE due to the higher flow rate thus offsetting its overall efficiency? This question could be addressed by comparing pressure drop in fluid flow in each loop.

The circulation pump installed in the main loop of the manifold is Taco $^{\circledR} 0013-F 3-1$ IFC. The pump curve provided by the manufacturer is shown in Fig. 6 . The measured flow rate for $\mathrm{BH} 2, \mathrm{BH} 3$ and $\mathrm{BH} 4$ is $9.5 \mathrm{GPM}, 11 \mathrm{GPM}$ and 14.5 GPM respectively. From the pump curve, the total head for coaxial BHE is about $6.6 \mathrm{~m}$. The average total head for the Uloop BHE is $7.7 \mathrm{~m}, 17 \%$ higher than the head of the coaxial BHE. Because the three BHs have the same length, the pressure drop per meter in the coaxial system is lower than that of the U-loop system. Therefore it can be deduced that the coaxial BHE has lower flow resistance than the U-loop BHE, and thus requires less mechanical pumping force in circulating the fluid.

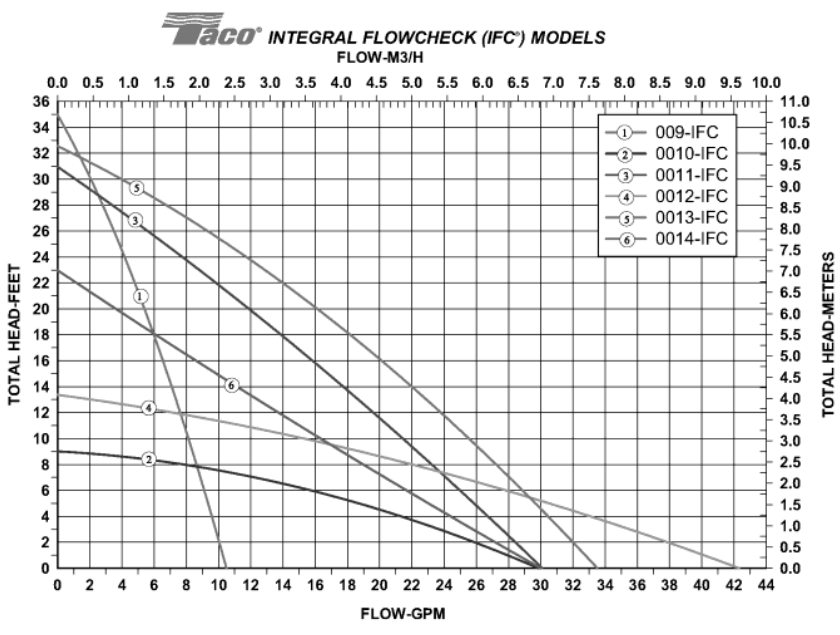

Figure 6. Taco IFC models circulation pump curve.

\section{BOREHOLE EFFICIENCY AND SYSTEM DESIGN}

While it is recognized that both ground thermal conductivity and borehole thermal resistance affect the performance of geothermal systems, the factor of borehole heat exchange efficiency is not properly addressed in design practice in geothermal industry. In North America, a small scale GSHP system "design" is usually based on a rule of thumb " $60 \mathrm{~m}$ per ton of refrigeration", without considering BHE efficiency.

In Europe, a German guideline VDI 4640 [5], summarized in Table VI, is applied in planning and design of a GSHP system up to $30 \mathrm{~kW}$ heating load. The specific heat transfer rate ranges between $20-100 \mathrm{~W} / \mathrm{m}$, depending only on underground soil and groundwater condition. Still, the effect of BHE efficiency is ignored. 
TABLE VI. SPECIFIC ENERGY EXTRACTION RATES BY VDI 4640 [5]

\begin{tabular}{|c|c|c|}
\hline \multirow{2}{*}{ Underground } & \multicolumn{2}{|c|}{ Specific heat extraction $(\mathrm{W} / \mathrm{m})$} \\
\hline & for $1800 \mathrm{~h} /$ year & for $2400 \mathrm{~h} /$ year \\
\hline general guideline values: & & \\
\hline $\begin{array}{l}\text { Poor underground (dry sediment) } \\
\left(K<1.5 \mathrm{~W} /\left(\mathrm{m}^{\circ}{ }^{\circ} \mathrm{C}\right)\right)\end{array}$ & 25 & 20 \\
\hline $\begin{array}{c}\text { Normal rocky underground and } \\
\text { saturated sediment } \\
\left(K<1.5-3.0 \mathrm{~W} /\left(\mathrm{m} \cdot{ }^{\circ} \mathrm{C}\right)\right)\end{array}$ & 60 & 50 \\
\hline $\begin{array}{l}\text { Consolidated rock with high } \\
\text { thermal conductivity } \\
\left(\mathrm{K}>3.0 \mathrm{~W} /\left(\mathrm{m}^{\circ}{ }^{\circ} \mathrm{C}\right)\right)\end{array}$ & 84 & 70 \\
\hline Overburden and bedrocks: & & \\
\hline Gravel, Sand (dry) & $<25$ & $<20$ \\
\hline Gravel, Sand (saturated) & $65-80$ & $55-65$ \\
\hline $\begin{array}{c}\text { Strong groundwater flow in gravel } \\
\text { and sand }\end{array}$ & $80-100$ & $80-100$ \\
\hline Clay, loam, wet & $35-50$ & $30-40$ \\
\hline Limestone (massif) & $55-70$ & $45-60$ \\
\hline Sandstone & $65-80$ & $55-65$ \\
\hline Siliceous magmatite (e.g. granite) & $65-85$ & $55-70$ \\
\hline Basic magmatite (e.g. basalt) & $40-65$ & $35-55$ \\
\hline Gneiss & $70-85$ & $60-70$ \\
\hline
\end{tabular}

One of the requirements in borehole loop length design is to ensure working fluid temperature in BHE is maintained above a minimum operating temperature $T_{\min }$ in heating mode and below a maximum temperature $T_{\max }$ in cooling mode, subjected to specifications of the heat pump.

For instance, in heating mode, if the selected temperature of water entering the heat pump (EWT) is:

- too high, the borehole length is oversized and the system is expensive;

- $\quad$ too low, the system will offer less energy savings and failure may occur in continuous operation.

Let the specific heat transfer rate from ground to $\mathrm{BHE}, \dot{q}$, be expressed in a simplified way in accordance with the borehole thermal resistance $R$ :

$$
\dot{q}=\frac{\dot{Q}}{L}=\frac{\left(T_{\mathrm{g}}-T_{\mathrm{f}}\right)}{R}=\frac{\Delta T}{R}
$$

where $\dot{Q}$ is the total heat transfer rate from ground to BHE (W); $L$ is the borehole length (m); $T_{\mathrm{g}}$ is the instant ground temperature at borehole wall $\left({ }^{\circ} \mathrm{C}\right) ; T_{\mathrm{f}}$ is the circulating fluid temperature in $\mathrm{BHE}\left({ }^{\circ} \mathrm{C}\right) ; R$ is the borehole thermal resistance $\left[{ }^{\circ} \mathrm{C} /(\mathrm{W} / \mathrm{m})\right] . \dot{q}<0$ when heat is injected into the ground from BHE.

The heat transfer rate $\dot{Q}$ in a GSHP system is fairly a constant, determined by the heating/cooling capacity and COP of the heat pump. Rearranging (1), one obtains

$$
\Delta T=\left(T_{\mathrm{g}}-T_{\mathrm{f}}\right)=R \dot{q}=\frac{R \dot{Q}}{L}
$$

Equation (2) indicates that temperature difference between ground and working fluid, $\Delta T$, is proportional to the borehole thermal resistance. A higher $\Delta T$ will be resulted if the thermal resistance of BHE is high. Fig. 7 and Fig. 8 show working fluid temperature variations with specific heat transfer rate, for different values of $\mathrm{BH}$ resistance $R$, in a cold climate and a hot climate respectively.

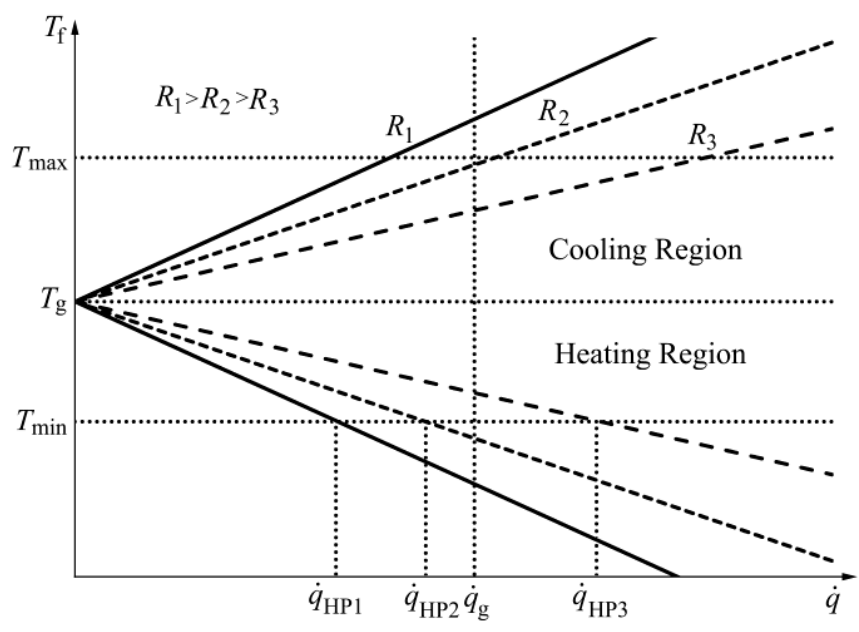

Figure 7. Fluid temperature and specific energy extraction in a cold climate.

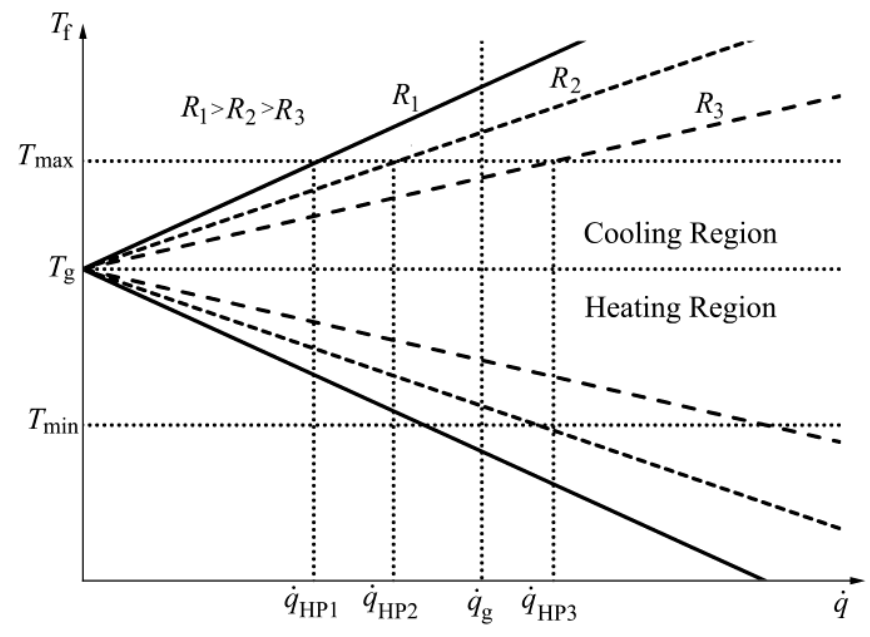

Figure 8. Fluid temperature and specific energy extraction in a hot climate.

The specific heat extraction rate $\dot{q}_{g}$, shown in Figs. 7 and 8 , is determined by the ground condition from Table VI. Depending on the climate condition and BHE efficiency, GSHP system designed by $\dot{q}_{g}$ only may or may not function properly.

Taking a cold climate as an example (Fig. 7), if a low resistance BHE $R_{3}$ is used, the fluid temperature would be above $T_{\min }$ in heating mode at specific heat extraction rate $\dot{q}_{g}$, and the HP will be able to operate normally. However, if a higher resistance $\mathrm{BHE} R_{1}$ is used, fluid temperature would drop to below $T_{\min }$ at specific heat extraction rate $\dot{q}_{g}$ and HP would fail to function in this case. A similar situation could be illustrated by Fig. 8 in a hot climate in cooling mode.

Therefore, other than $\dot{q}_{g}$ provided by Table VI, the specific 
heat transfer rates, $\dot{q}_{H P}$, associated with BHE resistances $R$ and HP working temperature range $T_{\min }$ and $T_{\max }$ must be determined in GSHP system design. The applicable design criterion of a GSHP system should be:

$$
\dot{q}<\min \left(\dot{q}_{g}, \dot{q}_{H P}\right)
$$

If a proper BHE is used such that $\dot{q}_{H P}>\dot{q}$, the system would be able to be designed on the maximum thermal capacity of the ground. In this case, the shorter borehole length dictated by the ground could be achieved, and the initial investment cost could be minimized.

Therefore, a high efficiency borehole heat exchanger not only saves daily operation expense, but also reduces the initial investment cost.

\section{CONCLUSIONS}

Based on the three sets of comparative tests, it is clearly shown that the coaxial BHE has a higher heat transfer capacity. For all the three sets of test, the single coaxial BHE performance can reach $94 \%-96 \%$ of the twin U-loop's. On the other hand, the single U-loop BHE performance is only $78 \%$ of the twin U-loop's.

It is also observed that the working fluid temperature of the single U-loop BHE test is significantly higher than the twin Uloop's in the comparative cooling mode test, whereas for the single coaxial BHE test, the temperature is only slightly higher than the twin U-loop's. As was discussed, the temperature difference between the ground and the working fluid, $\Delta T$, is proportional to the borehole resistance in a constant rate heat transfer process. Excessive temperature difference will cause low heat pump COP and must be avoided in the design.

When pressure drops of the two types of BHE are compared, the coaxial pipe showed a $17 \%$ average lower head loss, resulting a $40 \%$ higher flow rate at the same pumping force.

As was discussed, a higher borehole exchange efficiency not only improves system performance, but also reduces required borehole length, depending on the ground and climate condition. Therefore, the higher efficiency coaxial BHE has the potential to reduce borehole length $30 \%$ to $50 \%$.

\section{ACKNOWLEDGMENT}

The research was funded by McClymont \& Rak Engineers Inc. with assistance from the SRED program. The author is grateful for the continuing support by Christine Ermarkaryan of BDC. The author is also thankful to Fazin Rad and Matt Unwin for their work in system setting up and data monitoring.

\section{REFERENCES}

[1] J. Acuna, "Distributed thermal response tests-New insights on U-pipe and Coaxial heat exchangers in groundwater-filled boreholes," Doctoral Thesis, KTH School of Industrial Engineering and Management, Sweden, 2013.

[2] G. Hellstrom, "Borehole heat exchanges state of the art," Report IEA IA ECES Annex 13-Design, Construction and Maintenance of UTES Wells and Boreholes, 2002.
[3] S. Gehlin, "Thermal Response Test, method development and evaluation," Doctoral Thesis, Lulea University of Technology, Sweden, 2002.

[4] V. Minea, "Standing column heat pump without bleed in a cold climate," $10^{\text {th }}$ IEA Heat Pump Conference, 2011.

[5] VDI-Richtlinie, "Thermal use of the underground, Blatt 2," Düsseldorf, Verain Dertscher Ingerieure, VDI-Verlag, 2001.

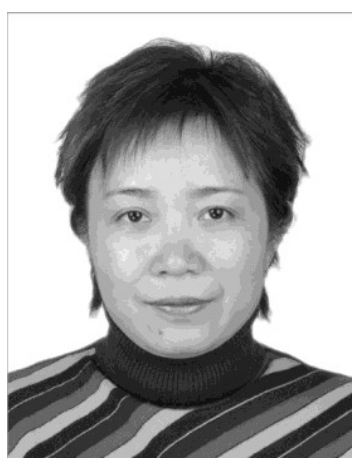

Jun Wang graduated with a Doctor of Philosophy degree in Mechanical Engineering from University of Hong Kong, Hong Kong, 1988.

Currently she works as a Research Scientist at McClymont \& Rak Engineers, Inc., Vaughan, Canada. She previously worked as a Professor at Huazhong University of Science \& Technology, Wuhan, China. Published book: Theory and Applications of Damage Mechanics, Beijing, China: Science Press, 1997. Research interests include green energy application and Finite Element Analysis.

Dr. Wang: The Amelia Earhart Fellowship Award, Zonta International, 1987. 